\title{
Neuroendoscopic Intervention for Deep Midline Brain Tumors with Secondary Occlusive Hydrocephalus
}

\author{
Ulugbek M. Asadullaev, PhD \\ Republican Research Center of Neurosurgery \\ Tashkent, Uzbekistan
}

\begin{abstract}
This article analyzes the results of a clinical examination of 102 patients $(78 / 76.47 \%$ men and $24 / 23.53 \%$ women) with a brain tumor (BT) complicated with a secondary obstructive hydrocephalus (SOH). All the patients were divided into 3 groups according to the type of surgery. Group 1 included 38(37.2\%) patients who underwent Torkildsen's ventriculocisternostomy. Group 2 consisted of 34(33.3\%) patients who underwent endoscopic third ventriculocisternostomy (ETV) with simultaneous endoscopic tumor removal. Group 3 included 30 (29.4\%) patients who underwent a two-stage intervention: ETV in the first stage, and the endoscopic tumor removal in the second stage. The distinct advantages of EVT with tumor removal in the second stage of the operation were revealed.
\end{abstract}

Keywords: brain tumor; secondary obstructive hydrocephalus; endoscopic third ventriculocisternostomy (ETV).

\section{Introduction}

Surgeries of deep midline brain tumors (BTs) remain one of the most difficult sections of clinical neurosurgery $[1,2]$. Characteristic features of BT with secondary obstructive hydrocephalus $(\mathrm{SOH})$ and the bright manifestation of hydrocephalus, so-called brain dropsy, require the solution of two important issues. First of all, elimination of a progressive manifestation of the hypertension-hydrocephalic syndrome (HHS) and SOH; second, microsurgical BT removal [2-4]. Traditional methods of surgical correction of HHS caused by occlusion of the cerebrospinal fluid (CSF) pathways (Torkildsen's ventriculocisternostomy (VCS), ventriculoperitoneostomy, ventriculoatriostomy) have a number of contraindications and are quite traumatic. Marked interventions often contribute to the development of severe complications, such as infection and occlusion of shunts, particularly in decompensated patients $[1,3]$. An alternative to these interventions for SON elimination in BT patients is endoscopic third ventriculocisternostomy (ETV), which contributes to the creation of new the CSF pathway, that provide drainage of excess CSF to subarachnoidal space via

*Corresponding author: Ulugbek M. Asadullaev, PhD. Republican Research Centre of Neurosurgery, Tashkent, Uzbekistan E-mail: asadullaevu@gmail.com cisterns [5-8]. The bypass surgery is mainly performed by leading neurosurgeons, as is ETV with simultaneous tumor removal. It should be noted that tumor removal at the second stage after SOH elimination, on the background of absence of the cerebral symptoms and relatively satisfactory patient's condition, is performed significantly less frequently, which is not always justified.

The purpose of this study was to compare the results of one- and two-stage surgical procedures after EVT and Torkildsen's ventriculocisternostomy (VCS) in patients with midline brain tumors complicated with $\mathrm{SOH}$.

\section{Material and Methods}

The study included 102 patients $(78 / 76.47 \%$ men and $24 / 23.53 \%$ women) with BT complicated with $\mathrm{SOH}$ treated in the Republican Research Centre of Neurosurgery (RRCN). All the patients were admitted with severe clinical symptoms of secondary hydrocephalus. Age of the patients ranged from 1.5 to 50 years: from 1.5 to 5 years in $4(3.9 \%)$ cases, from 6 to 15 years in $44(43.1 \%$ ) cases, from 16 to 25 years in $25(24.5 \%)$ cases, from 26 to 35 years in $19(18.6 \%)$ cases, and from 36 to 50 years in $10(9.8 \%)$ cases.

All the patients were divided into 3 groups according to the type of surgery. Group 1 included 38(37.2\%) patients who underwent VCS of Torkildsen. Group 2 consisted of 34(33.3\%) patients who underwent ETV with simultaneous endoscopic 
tumor removal. Group 3 included 30 (29.4\%) patients who underwent a two-stage intervention: ETV in the first stage, and the endoscopic tumor removal in the second stage; the second step was performed 5-35 days after elimination of SOH symptoms and stabilization of the patient's condition.

ETV was performed using video endosurgical complex "Aesculap" (Germany) and a set of standard microinstruments. Indication for ETV was the presence of open access to inferior part of the third ventricle. At the occlusion of the foramen of Monroe by BT in the anterior and middle regions of the third ventricle, the performance of EVT in most cases was impossible, and we performed VCS of Torkildsen. The length of the catamnestic observation time was from 3 to 12 months.

The clinical condition of the patients was assessed according to standard physical examination to determine neurological status. The severity of cerebral symptoms was determined by the complaints related to obstructive hydrocephalus: headaches, dizziness, nausea, uncontrollable vomiting, bradycardia, etc., as well as the results of a neuroophthalmic examination and MRI. The ophthalmological exam included in-depth study of the structures of the eye fundus. The severity of papilledema was assessed according to accepted standards of the Frisen grading scale. Severity of hydrocephalus was assessed in view of the state and sizes of the ventricles, the state of the subarachnoid space, and the degree of the periventricular edema according to MRI data. The results of surgery were assessed by the dynamics of clinical symptoms associated with regression of hydrocephalus, papilledema, and MRI signs of lesion. Before surgery, the condition of the ventricular system was assessed by neuroimaging techniques; all cerebral cisterns (interpeduncular, prepontine) were evaluated. The study was approved by the RRCN. Written informed consent was obtained from each patient. Statistical analysis was performed using the statistical software «Statistica». The difference was considered reliable when $P<0.05$.

\section{Results and Discussion}

For the development of $\mathrm{SOH}, \mathrm{BT}$ location and proximity to the CSF pathway had a paramount importance in comparison with the size and histological structure of BT. Among the 102 patients, severe hyrocephalic symptoms were observed in $81(79.4 \%)$ patients. An extremely critical condition, diffuse headaches, dizziness, nausea, vomiting, Bruns syndrome, bradycardia, and severe papilledema with retinal hemorrhage were observed in 21(20.58\%) patients. According to fundoscopy, Stage 1 of papilledema was detected in $38(37.2 \%)$ patients, stage 2 in $43(42.25 \%)$ patients, and stages 3-4 with signs of optic atrophy in $21(20.6 \%)$ patients. Moderate and severe bradycardia was detected in $36(76.6 \%)$ patients. Ventriculomegaly with symptoms of periventricular edema on $\mathrm{CT}$ and/or MRI brain imaging was determined in all patients.

The choice of surgical investigation was determined according to the level of the occlusion. Table 1 shows the distribution of patients according to the level of occlusion and surgery method. Comparative analysis of the clinical results of different methods of surgical interventions based on mortality, clinical deterioration, and clinical improvement is shown in Table 2. The distinct advantages of EVT according to all aspects should be noted; in addition, Group 3 patients who underwent tumor removal in the second stage of the operation were characterized by a significant advantage in comparison with the Group 1 patients. Patients of Group 3, after the endoscopic intervention, were in satisfactory condition and quickly recovered from anesthesia. Symptomatic relief of hydrocephalus was achieved in all patients. Furthermore, after surgery we observed in all patients a clear tendency to reduction of cerebral symptoms, a statistically significant decrease of diffuse headaches in $22(73.3 \%)$ patients, and the presence of local pain in the occipital region in $8(26.6 \%)$. After EVT, moderate dizziness persisted, but nausea and vomiting completely stopped. On the second and third days after the first stage of the intervention, a regression of disorders in the CSF circulation, according to CT and MRI data, was observed in most patients. Periventricular edema disappeared in all patients of Group 3 and a significant change in the size of the subarachnoid space was observed in $25(83.3 \%)$; reduction in the size of the ventricular system ("Flow void" phenomenon) in the area the anterior regions of the third ventricle and the stoma occurred in $14(46.76 \%)$ patients.

Table 1.

Distribution of patients according to the cause and the level of occlusion

\begin{tabular}{|l|c|c|c|c|c|c|}
\hline \multirow{2}{*}{$\begin{array}{c}\text { The causes of } \\
\text { SOD }\end{array}$} & \multicolumn{2}{|l|}{$\begin{array}{l}\text { The posterior } \\
\text { third ventricle } \\
\text { region and } \\
\text { aqueduct of } \\
\text { Sylvius }\end{array}$} & $\begin{array}{l}\text { Posterior fossa } \\
\text { region (fourth } \\
\text { ventricle, worm, } \\
\text { serebellar } \\
\text { hemisphere) }\end{array}$ & \multicolumn{2}{|c|}{ Amount } \\
\cline { 2 - 8 } & Abs & $\%$ & Abs & $\%$ & Abs & $\%$ \\
\hline $\begin{array}{l}\text { Tumors of the } \\
\text { pineal region and } \\
\text { quadrigemina }\end{array}$ & 6 & 28.6 & 15 & 71.4 & 21 & 20.6 \\
\hline $\begin{array}{l}\text { Posterior fossa } \\
\text { tumor }\end{array}$ & 10 & 12.3 & 71 & 87.6 & 81 & 79.4 \\
\hline Total & 16 & 15.7 & 86 & 84.3 & 102 & 100 \\
\hline
\end{tabular}

Table 2.

Outcomes of surgical treatment in the postoperative period in accordance with the method of surgical treatment

\begin{tabular}{|l|c|c|c|c|c|c|c|c|}
\hline \multirow{2}{*}{$\begin{array}{l}\text { Method of } \\
\text { surgery }\end{array}$} & \multicolumn{2}{|l|}{$\begin{array}{l}\text { Clinical } \\
\text { improvement }\end{array}$} & \multicolumn{2}{l|}{$\begin{array}{l}\text { Clinical } \\
\text { deterioration }\end{array}$} & \multicolumn{2}{l|}{ Mortality } & \multicolumn{2}{|l|}{ Amount } \\
\cline { 2 - 10 } & Abs & $\%$ & Abs & $\%$ & Abs & $\%$ & Abs & $\%$ \\
\hline $\begin{array}{l}\text { VCS of } \\
\text { Torkildsen }\end{array}$ & 15 & 39.5 & 14 & 36.8 & 9 & 23.8 & 38 & 37.2 \\
\hline $\begin{array}{l}\text { ETV with } \\
\text { simultaneous } \\
\text { endoscopic } \\
\text { tumor removal }\end{array}$ & 21 & 61.8 & 8 & 23.5 & 5 & 14.7 & 34 & 33.3 \\
\hline $\begin{array}{l}\text { ETV with } \\
\text { endoscopic } \\
\text { tumor removal in } \\
\text { the second stage }\end{array}$ & 22 & $73.3 *$ & 5 & $16.7 *$ & 3 & $10.0 *$ & 30 & 29.4 \\
\hline Total & 58 & 56.9 & 27 & 26.5 & 17 & 16.7 & 102 & 100 \\
\hline
\end{tabular}

$*_{-} P<0.05$ versus VCS of Torkildsen 


\section{Conclusion}

ETV is the best neurosurgical technique and should be considered as the initial treatment for BT complicated with $\mathrm{SOH}$. ETV excludes mechanical complications and lowers the risk of biological complications, which are characteristic for drainage operations. EVT leads to successful outcomes by ensuring an adequate internal drainage of the cerebrospinal fluid and maximum recovery of the CSF circulation. EVT with endoscopic tumor removal in the second stage of the operation, compared with the VCS of Torkildsen, which is accompanied by significant damage to the brain structure, provides additional benefits to normalize the clinical status on the background of the absence of cerebral symptoms.

\section{References}

1. Asadullayev UM. The choice of methods for treatment hydrocephalus at brain tumors and the clinical outcomes. Neurol 2012; 2:28-30. [Article in Russian].

2. Konovalov AN1, Pitskhelauri DI, Shishkina LV, Kopachev DN, Sanikidze AZ, Gavriushin AV, et al. Intraparenchymal brainstem schwannomas: report of three cases and literature review. Zh Vopr Neirokhir Im N N Burdenko 2013; 77(2):3543. [Article in Russian].

3. Omarov AD, Kopachev DN, Sanikidze AZ, Pitskhelauri DI, Panshin GA, Datsenko PV, et al. Treatment for hydrocephalus of the neoplastic etiology. State of the problem. Bulletin of the Russian Scientific Center of Radiology 2011,11. [Article in Russian]

4. Sanikidze AZ Microsurgical ventriculocisternostomy for surgery of deeply and mid-located brain tumors. Abstract of PhD Thesis. Moscow; 2014.

5. Gaab MR, Schroeder HW. Neuroendoscopic approach to intraventricular lesions. J Neurosurg 1998; 88(3):496-505.

6. Teo C, Young R 2nd. Endoscopic management of hydrocephalus secondary to tumors of the posterior third ventricle. Neurosurg Focus 1999; 7(4):e2.

7. Stachura K, Grzywna E, Kwinta BM, Moskała MM. Endoscopic third ventriculostomy - effectiveness of the procedure for obstructive hydrocephalus with different etiology in adults. Wideochir Inne Tech Malo Inwazyjne 2014; 9(4):586-95.

8. Hader WJ, Brooks BL, Partlo L, Hamilton M. Neuropsychological outcome after endoscopic third ventriculostomy. Can J Neurol Sci 2014; 41(6):729-34. 